\title{
Investigating the Influence of Web 2.0 Tools on the Group Cohesion of Pre-service Teachers
}

\author{
Esther Fomsi F. (PhD) \\ Department of Curriculum Studies/Educational Technology \\ Faculty of Education, University of Port Harcourt, Rivers State, Nigeria. \\ Kingdom Chukwudi Eke (PhD) \\ Federal College of Education (Technical) Omoku, Rivers State, Nigeria
}

doi: 10.19044/esj.2017.v13n7p335 URL:http://dx.doi.org/10.19044/esj.2017.v13n7p335

\begin{abstract}
The study investigated the Influence of Web 2.0 Tools on the Group Cohesion of Pre-service teachers in cooperative learning classroom. It adopted the two-group post-test only quasi experimental design. Task and social cohesion were the two dimensions of Group Cohesion that were studied. The sample was seventy (70) fourth year students from the Department of Educational Management, University of Port Harcourt, Rivers State, Nigeria. The sample size was seventy (70) fourth year students from one teaching option (Economics) in the Department of Educational Management who offered the course Computer in Education during the 2013/2014 session. It was an intact class. The technique used for selecting this sample was purposive sampling. The instrument for data collection was Group Cohesion Questionnaire designed by Carless and De Paola (2000). The internal consistency of the Group Cohesion Questionnaire was determined by the authors. Using a sample of students outside the study sample, the researcher used the split-half method to determine the reliability of the instrument. Cronbach's coefficient alpha was reported at .680. Research questions were answered using mean and standard deviation while hypotheses were analysed using Z-test. The results showed that there was no significant difference in the task and social cohesion of students who used web 2.0 technologies and those who did not. Though, the major findings showed that web 2.0 technologies did not significantly affect students' task and social cohesion, incidental findings showed that students' communication and information literacy skills were improved as they worked online. Thus, the researchers recommended that Web 2.0 technologies should be adopted in higher institutions.
\end{abstract}


Keywords: Web 2.0, Cohesion, Task cohesion, Social cohesion, Virtual teams.

\section{Introduction}

The World Wide Web (WWW) has had a very great influence on human communication. Beginning from the advent of its second generation, popularly known as Web 2.0, communication and collaboration among family and friends, businesses and customers, politicians and their followers, have greatly improved. Web 2.0 is a term is used to describe a host of applications used for commercial, entertainment, and learning purposes. Web 2.0 technologies such as forum, blogging, media sharing sites and social networking sites can be used to support small groups of students who work cooperatively to complete a learning task. With Web 2.0 technologies, students can access the web not only for course information but also to create collective knowledge through social interactions (Maloney 2007 cited in Ajjan and Harshorne, 2008). These applications allow users to interact and collaborate with each other in a virtual community. The use of web 2.0 in the classroom, be it virtual or face to face, encourages the 4 Cs: communication, collaboration, creativity and critical thinking. It encourages peer tutoring, which has been of great benefit to students. Thus, people can collaborate and share information in different learning environments. When students work in small groups, they are given opportunities to collaborate and even though they are separated by time and space, they could work cooperatively in virtual environments using web 2.0. Collaboration fosters cohesion.

Cohesion is a factor that affects performance of teams/groups. Cohesion refers to that which enables a group work unitedly towards achieving a goal and satisfying members' emotional needs. Carron, Brawley, and Widmeyer (1998) cited in Carron, Bray, and Eys (2001) defined it as “a dynamic process that is reflected in the tendency of a group to stick together and remain united in the pursuit of its instrumental objectives and/or for the satisfaction of member needs." Nelson and Quick, (2008) cited in Franz (2012) define cohesion as the glue that makes the members of a group stick together. Research shows that cohesive groups generally seem to outperform non-cohesive groups, and have greater job and personal satisfaction (McGrath, 1984 in Sanchez and Yurrebaso 2009). Studies have also shown that group cohesion has positive effects on an individual's contribution to a group (Carron, Colman, Wheeler, and Stevens, 2002 in Sanchez and Yurrebaso 2009). In view of this, it is important to understand the factors that promote cohesion. Several of these factors have been identified. Barnejee (2012) lists the following as factors that affect group cohesion:

- The size of the Group - small groups are more likely to form teams because they will be more cohesive. 
- Interdependence - groups that are more interdependent are more likely to become teams.

- Achievement of goals - groups may or may not institute goals, but the institution of clear goals is more likely to make teams out of groups.

- Management demands and pressures

- Group Anxiety - the perception of an outside threat or external pressure makes a group thrive and may give it an added or increased cohesion because increased anxiety may give it a heightened sense of interdependence.

\section{Dimensions of group cohesion}

Cohesion is a multidimensional concept. Several authors have created and discussed different dimensions of cohesion. In this study, however, the authors will be looking at two dimensions of cohesion: Task and social cohesion. Task cohesion is defined as the degree to which members of a team work together to achieve a specific and identifiable goal, that is, the sense of shared commitment to a groups' goal. Hall (2007) describes task cohesion or group integration as an indication of how well the team operates as a working unit. In other words, if a group bonds together to win a football tournament, or complete a group project it is focused on task. Characteristics of task cohesive groups include: highly motivated, shared purpose, success driven and high skill level.

Social cohesion on the other hand is defined as the degree to which members of a team like each other and enjoy personal satisfaction from being members of the team. Social cohesion determines the strength of interpersonal bonds among members. It is the bonding that exists between group members through social activities such as parties, gatherings, and so on. Characteristics of socially cohesive groups include: friendship, likeness, caring, emotional bonds, and social connection. However, MacCoun (1996) posits that task cohesion may be more important than social cohesion in enhancing group performance. After reviewing military and civilian studies of cohesion and performance, he concluded that it is task cohesion - not social cohesion - that drives group performance. He pointed out that when social cohesion is too high, deleterious consequences can result, including excessive socializing, groupthink (the failure of a highly cohesive group to engage in effective decision making processes), insubordination, and mutiny.

This could apply irrespective of the type of team whether working face-to-face or virtual. Teams that use web 2.0 technologies as a form of computer mediation are called virtual teams. 


\section{Virtual Teams}

The term virtual teams have been born as a result of telecommunications and advances in networking environments (Driskell, Radtke, and Salas 2003). There has been a lot of confusion as to what constitutes a virtual team. Driskell et al. (2003) use the term virtual team to refer to a team or group whose members are mediated by time, distance, or technology. They believe that when interdependent group members work together on a common task while they are spatially separated, they qualify as virtual teams. Martins, Gilson, and Maynard (2004) define virtual teams (VTs) as teams whose members use technology to varying degrees in working across locational, temporal, and relational boundaries to accomplish an interdependent task. Other closely related terms that have been used to describe this type of environment include computer-mediated communications (CMC) and computer-supported cooperative work (CSCW) (Driskell, et al. 2003). From the foregoing, it can be concluded that teams that work online using any form of computer mediation such as web 2.0 technologies are virtual teams. Virtual teams can use various types of technology in communicating. These include: desktop videoconferencing, email telephones, web sites, instant messaging, file- and application-sharing, electronic bulletin boards, group decision support systems, and real-time calendar/scheduling systems.

Over the years, though, it has been observed by the authors that when pre-service teachers are put together to work in groups they do not cooperate. A Pre-service teacher as used in this study is a student teacher who is still undergoing a training to be a teacher in the Faculty of Education. When given group tasks, several situations arise among them. These include unresolved conflicts within groups which threatens their cohesion and affects group performance and lack of commitment to group goals and objectives. This has become a challenge to most instructors.

\section{Objectives of the study}

The purpose of this study, therefore, is to investigate, the influence of web 2.0 on the group cohesion of pre-service teachers.

Specifically, the study intends to:

1. Investigate the relative effects of Web 2.0 technologies on the task cohesion of pre-service.

2. Determine the effects of Web 2.0 technologies on the social cohesion of pre-service teachers.

\section{Research Questions}

The research questions that guide the study are: 
1. What is the effect of Web 2.0 technologies on the task cohesion of pre-service teachers?

2. What is the effect of Web 2.0 technologies on the social cohesion of pre-service teachers?

\section{Hypotheses}

H0:1 There is no significant difference in the task cohesion of pre-service teachers who use web 2.0 technologies and those who do not.

$\mathrm{H} 0: 2$ There is no significant difference in the social cohesion of pre-service teachers who use web 2.0 technologies and those who do not.

\section{Methodology}

The sample used for this study was seventy (70) fourth year students from one teaching option (Economics) in the Department of Educational Management, Faculty of Education, University of Port Harcourt, Rivers State, Nigeria. The course adopted is a first semester 400 - level course titled Computer in Education. The study adopted the quasi experimental design which made use of a control and an experimental group. An instrument intended to determine students' ownership of mobile devices, technology competencies and attitude towards the use of web 2.0 in the class, was distributed to the students. Students who did not own mobile devices with regular Internet connectivity, who lacked technology competencies and who displayed a negative attitude towards the use of web 2.0 in the class were assigned to the face to face group, while the others were assigned to the online group. At the end of the course work, the Group Cohesion Questionnaire by Carless and De Paola (2000) was administered to the students to determine the level of task and social cohesion between the two groups. The research questions were answered using mean and standard deviation while the research hypotheses were analysed using Z-test. The Statistical Package for the Social Sciences (SPSS) was used for the analysis.

\section{Results}

Research Question 1: What is the effect of Web 2.0 technologies on the task cohesion of pre-service teachers in cooperative learning classrooms? Table 1: Post-test scores of the effect of Web 2.0 Technologies on Pre-service teachers' task cohesion

\begin{tabular}{|l|l|l|l|}
\hline Variables & Group & $\begin{array}{l}\text { Post-test } \\
\text { Mean Scores }\end{array}$ & SD \\
\hline \multirow{2}{*}{ Task Cohesion } & Web 2.0 group & 69.2 & 10.91 \\
\cline { 2 - 4 } & Face to face group & 70.77 & 7.9 \\
\hline
\end{tabular}


Table 1 shows that students taught using web 2.0 technologies had a task cohesion mean score of 69.2 and SD of 10.91 while those in the face-toface group had a mean score of 70.77 and SD 7.9.

Research Question 2: What is the effect of Web 2.0 technologies on the social cohesion of pre-service teachers in cooperative learning classrooms?

Table 2: Post-test scores of the effect of Web 2.0 Technologies on Pre-service Teachers' Social cohesion

\begin{tabular}{|l|l|l|l|}
\hline Variables & Group & $\begin{array}{l}\text { Post-test } \\
\text { Mean Scores }\end{array}$ & SD \\
\hline \multirow{2}{*}{ Social Cohesion } & Web 2.0 group & 69.2 & 10.91 \\
\cline { 2 - 4 } & Face to face group & 70.77 & 7.9 \\
\hline
\end{tabular}

As shown in table 2, students taught using web 2.0 technologies had a social cohesion mean score of 69.2 and SD of 10.9 while those in the faceto-face group had a mean score of 70.8 and SD 7.95.

Hypothesis 1: there is no significant difference in the task cohesion of preservice teachers who use web 2.0 technologies and those who did not.

Table 3: Z-test of the task cohesion of pre-service teachers who use Web 2.0 technologies and those who did not.

\begin{tabular}{|l|l|l|l|l|l|l|l|}
\hline Variables & N & Mean & $\begin{array}{l}\text { Std. } \\
\text { dev. }\end{array}$ & df & Z-cal & Z-tab & Remarks \\
\hline $\begin{array}{l}\text { Web group } \\
\text { group fo }\end{array}$ & 35 & 8.28 & 2.12 & 68 & 0.15 & 1.96 & $\begin{array}{l}\text { Not } \\
\text { significant }\end{array}$ \\
\hline $\begin{array}{l}\text { Face to face } \\
\text { group }\end{array}$ & 35 & 8.37 & 2.43 & & & & \\
\hline \multicolumn{7}{|c|}{$\mathrm{P}<0.05$}
\end{tabular}

Table 3 shows there is no significant difference in the task cohesion of students who used web 2.0 technologies and those who did not. The mean and SD of students who used web 2.0 technologies was 8.28 and 2.12 respectively, while the students in the face-to-face group had a mean achievement of 8.37 ( $S D=2.42)$. The $\mathrm{Z}$ - calculated value of 0.15 is less than the Z-critical value of 1.96. This implies that there is no significant difference in the task cohesion of the two groups. The null hypothesis which states that there is no significant difference in the task cohesion of preservice teachers who use Web 2.0 technologies and those who did not, was accepted.

Hypothesis 2: there is no significant difference in the social cohesion of pre-service teachers who use web 2.0 technologies and those who did not. 
Table 4: Z-test of the social cohesion of pre-service teachers who use Web 2.0 technologies and those who did not.

\begin{tabular}{|l|l|l|l|l|l|l|l|}
\hline Variables & $\mathbf{N}$ & Mean & $\begin{array}{l}\text { Std. } \\
\text { dev. }\end{array}$ & df & Z-cal & Z-tab & Remarks \\
\hline Web 2.0 group & 35 & 6.97 & 3.43 & 68 & 1.69 & 1.96 & $\begin{array}{l}\text { Not } \\
\text { significant }\end{array}$ \\
\hline $\begin{array}{l}\text { Face to face } \\
\text { group }\end{array}$ & 35 & 8.34 & 3.35 & & & & \\
\hline
\end{tabular}

Table 4 shows there is no significant difference in the social cohesion of students who used web 2.0 technologies and those who did not. The mean and SD of students who used web 2.0 technologies was 6.97 and 3.43 respectively, while the students in the face-to-face group had a mean achievement of $8.34(\mathrm{SD}=3.35)$. The $\mathrm{Z}$ - calculated value of 1.69 is less than the $\mathrm{Z}$-critical value of 1.96 . This means that there is no significant difference in the social cohesion of the two groups. The null hypothesis was accepted.

\section{Discussion}

\section{Effects of Web 2.0 technologies on the task cohesion of pre-service teachers in cooperative learning classrooms.}

Table 1 showed that the task cohesion of students who used web 2.0 technologies was lower (69.2) than those who did not (70.77). This implies that the degree to which members of the virtual team worked together was lower than the face-to-face team. Thus, the sense of commitment to the group's goal was higher in the face-to-face group than the virtual group. Similarly, table 3 showed there was no significant difference in the task cohesion of students who used web 2.0 technologies and those who did not. The Z- calculated value of 0.15 was less than the Z-critical value of 1.96. Thus, the null hypothesis was accepted. This finding could be as a result of the type of technology used (forum and facebook), and the frequency of the communication (Asynchronous). The interaction time length between group members is an important factor that affects cohesion. The longer time people spend together interacting while working on task could affect their cohesiveness. But the virtual teams were communicating asynchronously and not in real time. This could have affected their interaction patterns and thus their cohesiveness. This result is not a surprise because virtual teams have peculiarities that face-to-face teams do not have. In a study of student teams from multiple universities, Warkentin, Sayeed and Hightower (1997) cited in Martins et al. (2004) found that face-to-face groups reported higher levels of cohesiveness than did virtual teams. Driskell et al. (2003) cited studies that indicated that the distribution of team members over remote networks tends to impair team interaction in comparison with face-to-face interaction. One 
of such studies is by McLeod (1992) cited in Driskell et al. (2003) who found that computer-mediated interaction led to an increase in the time required to make a decision and a decrease in team member satisfaction.

Martins et al.(2004) mentioned that the type of technology used by virtual teams is an important input. Their review of literature showed that media richness has been found to positively impact team effectiveness, efficiency, amount of communication, the relationships among team members and team commitment. Thus Driskell et al. (2003) emphasize the fact that virtual teams may operate in different types of communication environments and that the type of communication environment implemented will have a significant impact on team interaction.

Straus and McGrath (1994) cited in Strauss (1997) carried out a study in which 72 three-person groups worked on idea generation, intellective, and judgment tasks in either computer-mediated (CM) or face-to-face (FTF) discussions. They found that in comparison to FTF groups, CM groups were less productive across tasks and expressed lower satisfaction in the judgment task. Thus CM groups expressed lower cohesiveness than did FTF groups. Olson and Olson (2000) cited in Driskell et al. (2003) thus concluded that distance could truly affect cohesiveness and that group members who are remotely located or distributed from one another are likely to face obstacles in coordinating group efforts.

\section{Effects of Web 2.0 technologies on the social cohesion of pre-service teachers in cooperative learning classrooms.}

Table 2 showed that the social cohesion of students who used web 2.0 technologies was lower (69.2) than those who did not (70.77). Their standard deviations were 10.91 and 7.9 respectively. This implies that the degree to which members of the virtual team liked each other was lower than the face-to-face group. Thus, the interpersonal bonds among the face-to-face team was stronger. Similarly, table 4 showed no significant difference in the social cohesion of students who used web 2.0 technologies and those who did not. The Z- calculated value of 1.69 was less than the Z-critical value of 1.96, thus the null hypothesis was accepted. This finding could be as a result of the communication pattern in the virtual team. Members of virtual teams are not exposed to individual characteristics of other members. Another possible reason for this result could be the richness of the media used. The web 2.0 technologies used for the study were forum and Facebook. Both technologies use asynchronous style of communication and lack the audio and visual aspect which contributes to media richness. Not communicating in real time - synchronously - and not seeing one another's gestures, facial expressions and other verbal cues could have equally affected students' social cohesion. 
This result is not surprising because studies have shown that attraction to a group and social cohesion to group members is greatly enhanced by exposure to the individual group members' characteristics. Groups who work in virtual teams using Web 2.0 technologies have less exposure to members' characteristics that they may find attractive or unattractive, which in turn affects their social cohesion. Straus (1997) suggested that group cohesion may be less variable in computer-supported groups because "group members will have less exposure to characteristics of others that they might find attractive or unattractive” (p. 237). Because in face-to-face groups members have greater access to information about other members'characteristics, in computer-supported groups differences and similarities will not be revealed on which levels of attraction can be based (Taylor and Macdonald, 2002).

Driskell et al. (2003) reviews studies that suggest that in contrast to face-to-face interaction in which individuating information on team members is abundant, members of virtual teams are more anonymous and deindividuated. Thus, interaction that is mediated by technology may lead to less intimacy and difficulty in establishing relationships among team members. This could lead to a weakening of social ties which in turn may lead to weaker affective bonds and a decrease in intimacy. This implies that in terms of interpersonal attraction, technological mediation may have a negative impact on cohesiveness. Similarly, in a study carried out by Taylor and Macdonald (2002), it was revealed that more group cohesion was perceived in groups receiving individuating information such as face-to-face groups. They posit that group cohesion may operate differently in computermediated groups and that the lack of nonverbal cues qualitatively affects interpersonal perception. Martins et al. (2004) equally cited studies that reveal that liking a team member was found to impact evaluations of the member's contributions in face-to-face groups but not in electronic groups, where a member's actual input was the most salient factor (Weisband \& Atwater, 1999 cited in Martins et al. (2004).

The major findings above show that web 2.0 technologies did not significantly affect students' task and social cohesion. This, though, does not mean that Web 2.0 technologies should not be adopted in higher education Institutions. The reason for this statement is because, in the course of the research, the authors incidentally found that the use of Web 2.0 technologies still offered other benefits to students. Those findings are discussed below and are termed incidental findings.

\section{Incidental findings}

- Students who were introverts and too shy to express their views in the face-to-face class were able to express themselves freely while 
working with web 2.0. They enjoyed collaborating with their instructors and peers and freely asked questions to get clarifications on concepts. This helped them to improve their communication skills - which are very vital survival skills in today's global economy.

- The use of Web 2.0 enhanced information literacy among the students. Most students lack the ability to search, retrieve and critically evaluate information. But the students who worked in virtual teams had to develop these information literacy skills because of the inexhaustive information from the web.

- A large percent of the students were interested in participating in course related online social media in the future. Most decided to use their virtual teams as reading groups in preparation for examinations.

- Most students in the face-to-face team later opted to join the virtual team.

\section{Conclusion}

Today's University students are engaged with an online world in an unprecedented way. Schools have to step up to the challenge of being at par with them there by providing them with the best educational resources possible (Best Education sites, 2014). The use of Web 2.0 technologies enables the development of the four Cs: Collaboration, Communication, Creativity and Critical thinking. It serves as a gateway to lifelong learning opportunities and should be adopted in Higher Education Institutions.

\section{Recommendations}

1. An awareness campaign should be carried out among students and educators on the use of web 2.0 technologies for academic purposes. Its use should not be limited to socializing. Using Web 2.0 for academic development would enable the development of a skill set that is compliant with $21^{\text {st }}$ century knowledge sharing and distribution.

2. Colleges and faculties in the University of Port Harcourt should create portals in the Universities website which would host blogs and discussion forum for educators and students. This would enhance communication and collaboration among educators and students.

3. Web-based activities and class-based wikis should be created using the University's website where students and educators can post comments, create content and share information. 


\section{References}

1. Ajjan, H. \& Hartshorne, R. (2008) Investigating faculty decisions to adopt web 2.0 technologies: Theory and empirical tests. Internet and Higher Education 11 (2008) 71-80.doi:10.1016/j.iheduc.2008.05.002

2. Banerjee, R.K . (2012) Factors that affect group cohesion. Retrieved $13^{\text {th }}$ November, 2016 from kb-lbc-09.blogspot.com/2009/11/factorsthat-affect-group-cohesion.html

3. Best Education Sites (2014) Schools that rule the infographic world. Retrieved $\quad 21^{\text {st }} \quad$ November, $2016 \quad$ from http://elearninginfographics.com/schools-rule-web-infographic/

4. Carless, S.A \& De Paola, C. (2000) The measurement of cohesion in work teams. Small Group Research, Vol. 31 No. 1, February 2000 71-88. Available at http://sgr.sagepub.com

5. Carron, A.V.; Bray, S. R.\& Eys, M.A.(2001) Team cohesion and team success in sport. Journal of Sports Sciences, Feb 2002 v20 i2 $\mathrm{p} 119(8)$. $\quad$ Retrieved $13^{\text {th }}$ October from http://www.montana.edu/craigs/team\%20cohesion

6. Driskell, J.E., Radtke, P.H., Salas, E. (2003) Virtual teams: effects of technological mediation on team performance. Group Dynamics: Theory, Research, and Practice , 2003, Vol. 7, No. 4, 297-323. Available at: http://limnology.wisc.edu/courses/zoo955/spring2008/LITERATUR E/COLLABORATORY/driskell2003_Virtual_Teams.pdf

7. Franz, T.M. (2012) Group dynamics and team interventions: understanding and improving team performance. Published by WileyBlackwell

8. Hall, A. (2007) Sport Psychology: Building group cohesion, performance and trust in athletic teams. Retrieved $13^{\text {th }}$ October from http://www.arichall.com/academic/papers/psy8840-sport-psyc.pdf

9. Mac Coun (1996) Unit Cohesion and Military performance. Retrieved $14^{\text {th }} \quad$ October from https://www.law.berkeley.edu/files/csls/Unit_Cohesion_and_Military _Performance_Ch5_MacCoun_Hix.pdf

10. Martins, L.L, Gilson, L.L., \& Maynard, M.T. (2004) Virtual Teams: What Do We Know and Where Do We Go From Here? Journal of Management 2004 30(6) 805-835 Available at: http://jom.sagepub.com /

11. Sánchez, J.C \& Yurrebaso, A. (2009) Group cohesion: relationships with work team culture. Vol. 21, n 1, pp. 97-104 ISSN 0214 - 9915 CODEN PSOTEG Retrieved $13^{\text {th }}$ November from http://www.psicothema.com/pdf/3601.pdf 
12. Straus, S.G. (1997) Technololgy, group process, and group outcomes: testing the connections in computer-mediated and face-toface groups. Journal of Human-Computer Interaction. Volume 12, Issue 3, September 1997, pages 227-266. Available at http://dl.acm.org/citation.cfm?id=1462977

13. Taylor, J. \& Macdonald, J. (2002) The effects of asynchronous computer-mediated group interaction on group processes. Social Science Computer Review, Vol. 20 No. 3, Fall 2002 260-274. Retrieved $17^{\text {th }}$

November fromhttp://www.seedwiki.com/accounts/dolansky_sara_24405/Async hronousEffectsOnGroupProcesses.pdf 